\title{
PENGARUH PERMAINAN TRADISIONAL GOBAK SODOR DALAM BIMBINGAN KELOMPOK TERHADAP PENINGKATAN INTERAKSI SOSIAL ANAK AUTIS
}

\author{
Fifi Khoirul Fitriyah ${ }^{1}$, Mustofa ${ }^{2}$ \\ Universitas Nahdlatul Ulama Surabaya \\ fifi@unusa.ac.id \\ mustofa@unusa.ac.id
}

\begin{abstract}
Abstrak
Prevalensi autis baik di Indonesia maupun dunia sedang mengalami peningkatan dari tahun ke tahun. Hal ini menyebabkan masalah autisme menjadi masalah serisu bukan hanya di bidang kesehatan yang juga pendidikan. Hingga kini, penyebab autisme belum dapat dipastikan yang diterapkanpun belum optimal. Melalui implementasi bimbingan dan konseling di sekolah, guru berusaha untuk mengatasi masalah yang dialami anak autis khususnya masalah rendahnya kemampuan interaksi sosial. Tujuan penelitian ini adalah mendukung permainan gobak sodor dalam kelompok untuk meningkatkan kemampuan sosial anak autis. Penelitian ini menggunakan kuantitatif dengan desain subjek tunggal tipe AB. Hasil penelitian ini menunjukkan adanya peningkatan kemampuan interaksi sosial anak setelah penerapan permainan gobak sodor dalam bimbingan kelompok, Selain itu, temuan baru dari penelitian ini adalah melibatkan partisipasi anak dalam membangun interaksi dengan anak autis. Hal ini benar-benar positif untuk kedua belah pihak yaitu pada anak autis dan juga anak normal yang setuju dalam permainan.
\end{abstract}

Kata Kunci: Autis, Bimbingan Kelompok, Gobak Sodor, Interaksi Sosial

\begin{abstract}
:
The prevalence of autism in both Indonesia and the world is increasing from year to year. This causes the problem of autism to be a serious problem not only in the health sector but also in education. Until now, the cause of autism can not be ascertained even that the solution is not optimal. Through the implementation of guidance and counseling in schools, teachers try to overcome the problems of autistic children, especially the problem of low social interaction abilities. The purpose of this study is to test Gobak Sodor Game in group guidance to improve the social interaction abilities of children with autism. This study uses quantitative with a single subject type $\mathrm{AB}$ design. The results of this study indicate an increase in the social interaction ability of autism children after the implementation of Gobak Sodor Game in group guidance. In addition, new findings from this study involve children's participation in building interactions with autistic children. This is really positive for both parties, namely autistic children and also normal children who join in the game.
\end{abstract}

Keywords: Autism, Group Guidance, Gobak Sodor, Social Interaction 


\section{PENDAHULUAN}

Autism spectrum disorder (ASD) merupakan gangguan perkembangan yang meliputi gangguan dalam interaksi sosial, komunikasi, dan adanya minat yang terbatas serta perilaku berulang (repetitive behaviors) (American Psychiatric Association, 2013). Center for Disease Control and Prevention saat ini memperkirakan rata-rata 1 dari 68 anak di Amerika Serikat mengalami ASD dan mengalami peningkatan dari trend sebelumnya (CDC, 2014). Di Indonesia, sejak tahun 2010 jumlah autisme mengalami peningkatan setiap tahunnya sekitar 500 kelahiran. Pada tahun 2015 diperkirakan jumlah autism di Indonesia mencapai 12.800 anak (Harnas.co, 2 April 2018).

Individu dikatakan mengalami autisme ketika mengalami dua kriteria dari seluruh krtiteria yang disebutkan dalam Diagnostic Statistic Manual (DSM-IV). Dalam aspek interaksi sosial dan komunikasi yang merupakan masalah khas yang diamali autism, Individu harus memenuhi semua kriteria komunikasi dan interaksi sosial yang meliputi masalah interaksi sosial dan emosional, masalah dalam mempertahankan interaksi dan hubungan, dan masalah dalam melakukan komunikasi non-verbal. Lai (2014) menyebutkan gejala-gejala lain yang terkait dengan gangguan ASD adalah mudah marah, hiperaktif, agresif, kecemasan, gangguan suasana hati, dan insomnia. Begitu banyak gejala ASD yang muncul dan menyertai, di sisi lain penyebab autisme hingga saat ini belum diketahui secara pasti. Atladottir et al. (2010) menyebutkan penyebab ASD adalah akibat infeksi pada masa prenatal.
Selain itu, faktor genetik juga diduga menjadi penyebab ASD (Hallmayer et al., 2011; Miles, 2011).

Anak autis dan anak berkebutuhan khusus lainnya di Indonesia mendapatkan layanan pendidikan selayaknya anakanak lainnya yakni melalui pendidikan inklusif (Permendiknas RI Nomor 70 Tahun 2009 Pasal 1 tentang Pendidikan Inklusif, 2009). Dalam peraturan menteri nomor 111 tahun 2014 mempertegas peran bimbingan dan konseling di sekolah yang juga membawahi jenjang sekolah dasar dan juga sekolah luar biasa maupun inklusif. Sehingga dalam penyelenggaraannya diperlukan adanya kerjasama guru kelas, guru bimbingan dan konseing, psikolog dan pihak-pihak lain yang terkait dengan masalah yang dihadapi anak didik. Masalah utama yang menjadi fokus penelitian ini adalah kemampuan interaksi sosial pada anak autis. Masalah tersebut termasuk dalam masalah sosial sehingga intervensi dari permasalahan tersebut harus berbasis kelompok.

Bimbingan kelompok merupakan layanan paling tepat dalam mengatasi masalah interaksi sosial anak autis. Berbeda dengan layanan bimbingan kelompok pada umumnya, bahwa bimbingan kelompok kali ini akan melibatkan anak normal dalam pelaksanaannya. Peran anak normal dalam kegiatan kelompok mampu membantu anak autis dalam berinteraksi sosial (McConnell, 2002; Chawarska \& Frederick, 2009). Bimbingan kelompok memiliki banyak teknik, salah satunya adalah terknik bermain. Karena dunia anak adalah bermain maka teknik ini dipilih. Permainan yang digunakan dalam 
intervensi ini adalah gobak sodor. Model permainan gobak sodor ini dikembangkan agar sesuai diterapkan untuk anak autis, serta mampu meningkatkan kemampuan interaksi sosialnya. Tujuan penelitian ini adalah menguji implementasi bimbingan kelompok menggunakan teknik permainan gobak sodor untuk meningkatkan kemampuan interaksi sosial anak autis.

Berdasarkan DSM-IV, kemampuan interaksi sosial pada autis merupakan masalah utama yang perlu segera diselesaikan, selain masalah gangguan perilaku dan terbatasnya minat dalam beraktivitas (DSM-IV, 1994). Kemampuan interaksi sosial merupakan salah satu kemampuan yang harus dimiliki setiap individu untuk dapat membina hubungan yang baik dengan individu lainnya. Selain itu, kemampuan interaksi sosial merupakan ujung tombak untuk dapat menyeseuakan diri dengan lingkungan (Peeters, 2009; Walton \& Brooke, 2013).

Berbagai intervensi mulai dari pengobatan, terapi psikologis, diet, dan penanganan dini bagi anak autis telah diterapkan (Wagino, dkk., 2006). Sedangkan Kang-Yi, Roy, \& David (2013) melalui penelitiannya menghimbau adanya prosedur diagnosis yang tepat untuk anak autis guna menentukan intervensi sedini mungkin. Clifford, et al. (2013) memperkuat pernyataan tersebut bahwa deteksi gangguan autisme dapat dilakukan sedini mungkin yakni sejak bayi melalui level tempramen mereka.
Berdasarkan penelitian-penelitian terdahulu, yakni sebanyak 1.217 penelitian subyek tunggal menguji efektivitas dari sebuah intervensi untuk menangani autisme. Berdasarkan datadata tersebut ditemukan bahwa intervensi psikososial mampu membawa dampak positif bagi perilaku autis (BishopFitzpatrick et al, 2013). Salah satu kriteria dalam penerapan intervensi psikososial adalah melalui dukungan kelompok sehingga dapat melatih anak autis dalam berinteraksi dengan lingkungan sosialnya.

Berdasarkan kajian-kajian layanan bimbingan dan konseling di sekolah, layanan bimbingan kelompok merupakan layanan yang paling tepat untuk menangani masalah interaksi sosial anak autis. Umumnya layanan bimbingan kelompok digunakan untuk meningkatkan kapasitas dan kemampuan anak-anak normal, namun dalam penelitian ini layanan bimbingan kelompok digunakan untuk menangani anak autisme sehingga membutuhkan adanya modifikasi.

Teknik yang digunakan yakni teknik bermain menggunakan permainan gobak sodor. Permainan gobak sodor adalah sebuah permainan kompetisi yang menekankan kerjasama antar anggota dalam kelompok. Permainan ini terdiri dari dua kelompok yakni kelompok jaga dan kelompok penyerang. Setiap pemain dalam kelompok jaga bertugas untuk berjaga dengan membuat penjagaan berlapis sambil merentangkan tangan agar tidak dapat dilalui lawan, satu pemain di garis tengah yang bergerak lurus dari penjagaan lainnya. Sedangkan kelompok penyerang berusaha untuk 
menerobos pertahanan kelompok jaga. Setiap daerah memiliki permainan yang pelaksanaannya hamper sama atau banyak persamaan dengan permainan di daerah lainnya. Tentang nama permainan kadang sama kadang juga berbeda, padahal pelaksanaan dan aturan permainannya sama. Contoh, permainan dengan nama "gobak sodor" dikenal di Jawa Tengah, sedangkan di Jakarta permainan ini disebut "Galasin", dan di Sumatera disebut "Margalah". Karena memiliki aturan permainan yang sama dan pelaksanaan yang sama, maka Direktur Keolahragaan memberi nama permainan tersebut dengan nama permainan hadang. Nama hadang ditetapkan berdasarkan hasil pengamatan, bahwa di dalam permainan ini tugas pemain adalah menghadang (Soemitro, 1992:172).

\section{METODE PENELITIAN}

Pendekatan penelitian ini adalah penelitian kuantitatif dengan menggunakan desain subjek tunggal. Tujuan penelitian ini adalah untuk mengetahui adanya peningkatan skor kemampuan interaksi sosial pada anak autism, sehingga rancangan eksperimental perlu dirumuskan dalam penelitian ini. Subjek penelitian adalah tiga anak autis yang bersekolah di salah satu sekolah dasar inklusif di Surabaya. Tiga anak autis yang dipilih sebagai subjek penelitian ini adalah mereka yang memiliki keterampilan interaksi sosial yang rendah. Subjek-subjek tersebut adalah GRR, WWD, dan ALK.

Dalam penelitian ini, kemampuan interaksi sosial didefinisikan sebagai kemampuan komunikasi verbal dan non- verbal. Soekanto (2007) mendefinisikan kemampuan interaksi sosial adalah hubungan yang dinamis baik antar individu, antar kelompok, maupun antara individu dan kelompok. Dua aspek kemampuan interaksi sosial yang dominan adalah kontak sosial dan komunikasi. Pada kenyataannya, definisi kontak sosial dan komunikasi memiliki arti yang sama, sehingga dipilih salah satunya untuk pengukuran. Dalam penelitian ini aspek yang dipilih yakni komunikasi yang memiliki arti sebuah proses pengiriman pesan dan perasaan baik secara verbal dan non-verbal. Teknik pengumpulan data menggunakan pedoman observasi dan analisis data menggunakan statistik deskriptif.

\section{HASIL PENELITIAN DAN PEMBAHASAN}

\section{Hasil Penelitian}

Mengukur kemampuan interaksi sosial pada anak autis tidaklah mudah. Anak autis sering kali merasa tidak nyaman dengan kehadiran peneliti dan memang sulit menerima kehadiran orangorang baru. Hal ini menyebabkan peneliti sebelum melaksanakan proses penelitian melakukan pendekatan terlebih dahulu selama satu minggu, dimulai pada pukul 08.00 WIB hingga pukul 12.00 WIB. Yang dilakukan peneliti saat itu adalah mengikuti proses belajar mengajar di kelas bersama dengan subjek penelitian, sehingga dimungkinkan adanya interaksi antara subjek penelitian dengan peneliti. Proses pengembangan hubungan ini berhasil dengan sukses, hal ini ditandai dengan subjek-subjek penelitian menerima kehadiran peneliti dan bersedia 
menjalin komunikasi baik verbal maupun non-verbal.

Setelah pembentukan hubungan terjalin dengan baik antara peneliti dengan anak autis, selanjutnya adalah pengukuran kondisi baseline. Pengukuran kondisi baseline dilakukansebanyak enam kali dalam enam hari (lihat grafik 1). Setelah diketahui kondisi baseline, selanjutnya peneliti melanjutkan dengan penerapan intervensi melalui layanan bimbingan kelompok dengan teknik bermain menggunakan permainan "gobak sodor". Dalam implementasinya, peneliti melibatkan anak normal untuk bergabung dalam permainan ini. Dalam kondisi intervensi, peneliti melakukan pengukuran intervensi dan ditemukan data sebagaimana pada grafik 1 .

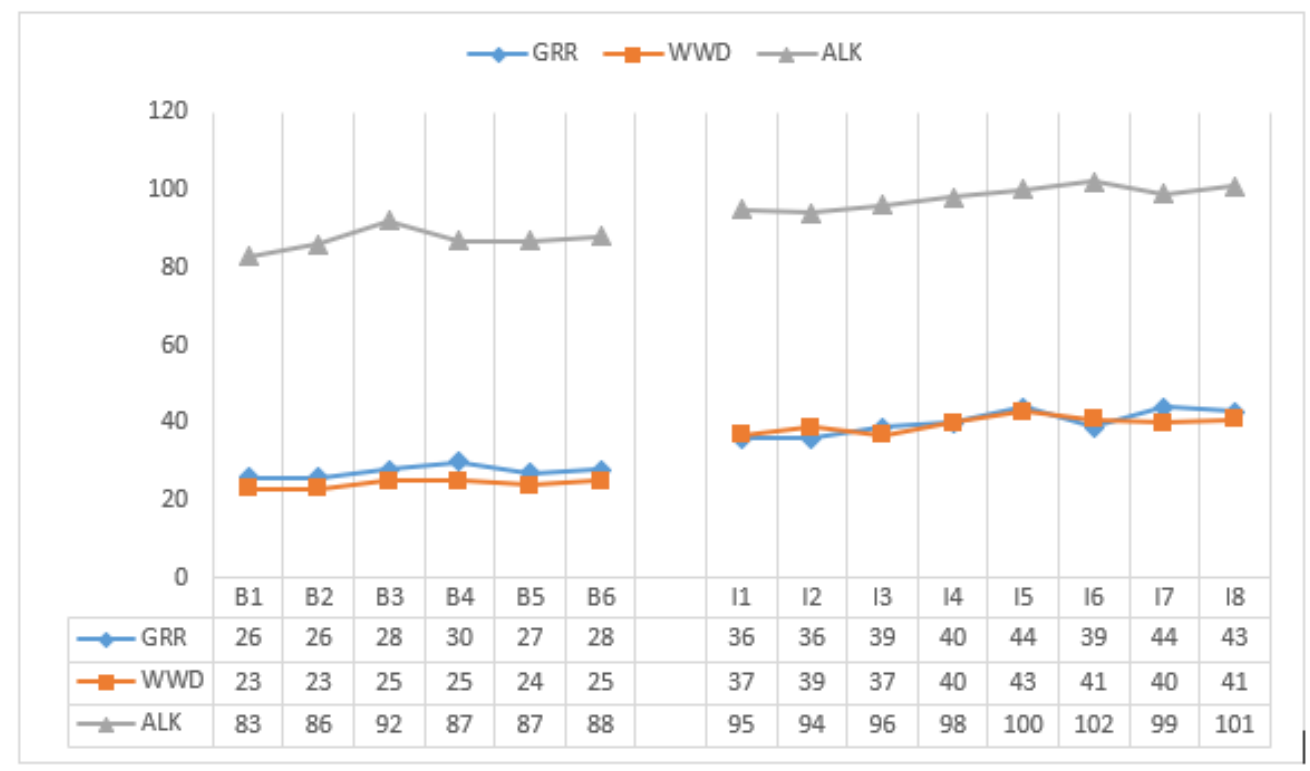

Grafik 1. Grafik perbandingan kondisi baseline dan intervensi kemampuan interaksi sosial anak autis

\section{Pembahasan}

Ada perbedaan yang signifikan antara anak autis dan anak normal dalam hal interaksi sosial dan kecenderungan stress mereka. Anak autis cenderung menunjukkan respon stress yang lebih tinggi dibandingkan dengan anak normal pada umumnya pada saat melakukan interaksi sosial. Selain itu, anak normal lebih memiliki minat untuk melakukan interaksi sosial dibandingkan dengan anak autis (Schupp, et al., 2013).

DSM-IV (1994) mendefinisikan kemampuan interaksi sosial sebagai kemampuan dalam hal: (1) perilaku non- verbal seperti kontak mata, ekspresi wajah, gesture tubuh, dan isyarat-isyarat lain dalam berinteraksi sosial. (2) Mengembangkan hubungan pertemanan dengan teman seusia, (3) mampu merasakan empati baik gembira maupun bersedih, dan (4) ada interaksi timbal balik dengan orang lain. Dalam DSM-IV juga menjelaskan tentang masalahmasalah interaksi sosial sebagai berikut: (1) Ketidakmampuan menjalin interaksi sosial secara memadai, (2) tidak mampu bermain dan berelasi dengan teman seusianya, (3) Tidak mampu berempati, 
dan (4) ketidakmampuan dalam berhubungan sosial timbal balik.

Peranan individu normal sangat diperlukan dalam pembentukan seting kelompok untuk intervensi autism. Hasil penelitian Chawarska \& Frederick (2009) dan McConnell (2002) menyebutkan bahwa anak autisme akan dapat terbantu melalui peranan aktif anak-anak normal dalam kelompok. Disisi lain yang perlu diperhatikan dalam hal interaksi sosial dengan anak autis adalah mereka mengalami kesulitan dalam memahami insyarat non-verbal sehingga disarankan untuk menggunakan isyarat verbal (Ames \& Chris, 2009).

Layanan pendidikan di sekolah bagi anak autis salah satunya adalah melalui bidang bimbingan dan konseling. Layanan bimbingan kelompok dipilih dalam penelitian ini dengan alasan anak autis dalam meningkatkan kemampuan interaksi sosialnya membutuhkan adanya dinamika kelompok. Jika dibandingkan dengan layanan konseling kelompok yang merupakan layanan lain dengan seting kelompok, layanan bimbingan kelompok masih lebih tepat. Hal ini disebabkan karena rendahnya kesadaran anak autis sehingga akan sulit untuk melakukan konseling kelompok. Dari segi tujuan, layanan bimbingan kelompok juga sesuai diterapkan untuk meningkatkan kemampuan interaksi sosial anak autis.

Bermain adalah salah satu teknik yang digunakan dalam implementasi bimbingan kelompok. Tujuan teknik bermain dalam implementasi bimbingan kelompok adalah menjadikan anak autis mampu mengatasi konflik-konflik dirinya melalui proses bermain yang didalamnya memiliki unsur terapeutik sehingga mampu membentuk perilaku baru bagi anak autis (Cramer, dkk dalam Delphie, 2005).
Sebelum permainan dimulai, tahapan yang dimulai adalah membentuk kelompok yang terdiri dari 3 anak autis dan 6 anak normal. Pembentukan kelompok yang heterogen ini dimaksudkan untuk meningkatkan fungsi kelompok. Terdapat empat tahapan yang dilalui, dan tahapan kegiatan diisi dengan implementasi permainan gobak sodor.

Dalam permainan, anak autis mampu menirukan gerakan anak lain. Grecucci, et al. (2013) menyatakan bahwa anak autis mampu melakukan aktivitas meniru gerakan yang dilakukan oleh anak lain atau biasa disebut dengan action resonance mechanism. Memberikan intruksi pada anak autis tidak semudah memberikan intruksi pada anak normal karena lebih sulit. Namun jika dibandingkan dengan anak yang mengalami keterbelakangan mental, anak autis cenderung lebuh mampu dalam interaksi sosial. Zalla, et al. (2013) menyebutkan bahwa anak autis dengan gangguan perkembangan khas atau typical development (TD) lebih mampu memahami suatu peristiwa dibandingkan dengan individu yang mengalami keterbelakangan mental.

\section{SIMPULAN DAN SARAN}

Adapun kesimpulan penelitian ini adalah adanya pengaruh positif permainan gobak sodor dalam bimbingan kelompok untuk meningkatkan kemampuan interaksi sosial anak autis, Selain itu, temuan baru dari penelitian adalah pentingnya melibatkan anak normal dalam membangun interaksi dengan anak autis. Hal ini ternyata berdampak positif kepada kedua belah pihak yakni pada anak autis maupun juga anak normal yang berpartisipasi dalam permainan.

Adapun saran untuk peneliti selanjutnya adalah: (1) Perlu adanya penelitian eksperimen untuk mengukur 
efektivitas permainan gobak sodor dalam bimbingan kelompok secara lebih luas, dan (2) Perlu dilakukan penelitian tentang pengaruh permainan gobak sodor dalam bimbingan kelompok untuk mengatasi permasalahan anak autis yang lainnya misalnya dalam membantu perkembangan motorik kasar anak autis, emosi positif, dan empati.

\section{DAFTAR RUJUKAN}

Autism and Developmental Disabilities Monitoring. (2012). National Center on Birth Defects and Developmental Disabilities. Community Report From the Autism and Developmental Disabilities Monitoring (ADDM) Network : Centers for Disease Control and Prevention (CDC), U.S. Department of Health and Human Services.

Ames, Catherine S., dan Chris Jarrold. (2009). Identifying Symbolic Relationship in Autism Spectrum Disorders: A Deficit in the Identification of Temporal Cooccurrence? Journal of Autism and Developmental Disorders, Desember 2009, Volume 39, Issue 12, pp 1723-1734.

Bishop-Fitzpatrick, et al. (2013). A Systematic Review of Psychosocial Intervention for Adults with Autism Spectrum Disorders. Journal of Autism and Developmental Disorder, March 2013 Volume 43 Issue 3 pp 687694.

Chawarska, Katarzyna., dan Frederick Shic. (2009). Looking But Not Seeing: Atypical Visual Scanning and Recognition of Faces in 2 and 4-Year-Old Children with Autism Spectrum Disorder. Journal of Autism and Developmental Disorders, Desember 2009,
Volume 39, Issue 12, pp 17231734.

Clifford, et al. (2013). Temprament in the First 2 Years of Life in Infants at High-Risk for Autism Spectrum Disorders. Journal of Autism and Developmental Disorder, March 2013 Volume 43, Issue 3, pp 673686.

Delphie, Bandi. 2005. Bimbingan Konseling untuk Perilaku Non Adaptif. Bandung: Pustaka Bani Quraisy.

Diagnostic and Statistical Manual of Mental Disorder, Fourth Edition (DSM-IV). (1994). Washington, DC. : American Psychiatric Association.

Eack, Shaun M., et al. (2013). Brief Report: Is Cognitive Rehabilitation Needed in Verbal Adults with Autism?. Journal of Autism and Developmental Disorder, February 2013.

Fitriyah, Fifi Khoirul. (2017). Reducing Aggressive Behaviour using Solution Focused Brief Counseling. JBKI (Jurnal Bimbingan Konseling Indonesia) 2 (2), 34-39, DOI:

http://dx.doi.org/10.26737/jbki.v2i 2.254 .

Grecucci, Alessandro., et al. (2013). Emotional Resonance Deficits in Autistic Children. Journal of Autism and Developmental Disorder, March 2013, Volume 43, Issue 3, pp 616-628.

Kang-Yi., et al. (2013). Korean Culture and Autism Spectrum Disorders. Journal of Autism and Developmental Disorder, March 2013, Volume 43, Issue 3, pp 503520.

McConnell, Scott R. (2002). Interventions to Facilitate Social Interaction for Young Children 
with Autism: Review of Available Research and Recommendations for Educational Intervention and Future Research. Journal of Autism Developmental Disorders, Vol. 32, No. 5, 2002.

Peraturan Menteri Pendidikan Nasional tahun 2009 tentang Pendidikan Inklusif

Peraturan Menteri Pendidikan dan Kebudayaan Nomor 111, tahun 2014.

Peeters, Theo. Tanpa Tahun. Panduan Autisme Terlengkap. Terjemahan oleh Oscar H. Simbolon dan Yayasan Suryakanti-Bandung. 2009. Jakarta: PT. Dian Rakyat.

Schupp, Clayton W., et al. (2013). Cortisol Responsivity Differences in Children with Autism Spectrum Disorders During Free and Cooperative Play. Journal of Autism and Developmental Disorder, February 2013.

Scahill, Lawrwnce., et al. (2013). Brief Report: Social Disability in Autism Spectrum Disorder: Result from Research Units on Pediatric Psychoppharmacology (RUPP) Autism Network Trials. Journal of Autism and Developmental Disorder, March 2013 Volume 43, Issue 3, pp 739-746.

Walton, Katherine M., dan Brooke R. Ingersoll. (2013). Improving Social Skills in Adolescent and Adult with Autism and Severe to Profound Intellectual Disability: A Review of the Literature. Journal of Autism and Developmental Disorder, March 2013, Volume 43, Issue 3, pp 594-615. 